\title{
Apego e comunicação: considerando o desenvolvimento infantil sob a ótica da etologia e da psicanálise
}

\author{
Julia Braga do P. Fernandes* (1) \\ Carlos Augusto Peixoto Junior $($ )
}

Pontifícia Universidade Católica do Rio de Janeiro. Rio de Janeiro, RJ, Brasil

\begin{abstract}
Resumo: Este artigo tem como objetivo abordar o vínculo primário da criança com sua mãe, colocando-o como primordial no desenvolvimento humano. Sob a ótica interdisciplinar da etologia e da psicanálise, discutem-se as noções de períodos sensíveis, estampagem e comportamento de apego, estabelecendo um paralelo entre os desenvolvimentos animal e humano. Em seguida, disserta-se sobre os modos de comunicação e suas raízes nas relações de apego que o indivíduo estabelece no início da vida, levando-se em consideração a clínica psicanalítica com o auxílio da teoria etológica.
\end{abstract}

Palavras-chave: teoria do apego, comunicação, etologia, psicanálise, teoria do apoio.

\section{Introdução}

Freud, em suas primeiras publicações, dedicou-se ao estudo da histeria com o intuito de investigar os fatores psíquicos que levavam um indivíduo a apresentar sintomas corporais inabituais e sem explicações orgânicas. Seu estudo levou, como sabemos, à compreensão de que tais sintomas estavam ligados a impulsos sexuais reprimidos que, mediante a impossibilidade de serem elaborados psiquicamente, apareciam no corpo. Diante disso, Freud se dedica mais aos aspectos sexuais presentes na ontogênese do indivíduo, valorizando principalmente a sexualidade infantil, que seria o ponto de partida para as manifestações posteriores na vida adulta. A histeria permanece ao longo dos primeiros quinze anos das publicações freudianas como principal referencial teórico, clínico, psicopatológico e epistemológico.

Em seu artigo "Três ensaios sobre a teoria da sexualidade", Freud (1905/2006) aponta três grandes escopos teóricos que norteiam o estudo sobre a teoria da sexualidade. No segundo ensaio, sobre a sexualidade infantil, ao investigarem as fases oral, anal e fálica, Abraham e Freud estipulam algumas balizas para a teoria psicanalítica que ganham força ao longo das décadas. Um dos pontos abordados nos "Três ensaios sobre a teoria da sexualidade" é a ideia de autoerotismo, que se torna controversa para alguns autores posteriores. Ao discutir o assunto, Freud aponta que, nesta prática, a pulsão não está dirigida para outra pessoa, ou seja, que ela se satisfaz no próprio corpo, sendo, portanto, autoerótica. Chupar o dedo exemplifica a ideia do autor de que este movimento se baseia em alguma sensação

* Endereço para correspondência: juliab.patrocinio@gmail.com de prazer vivenciada pela criança no ato de mamar: "A satisfação da zona erógena [a boca] deve ter se associado com a necessidade de alimento. A atividade sexual apoia-se primeiramente numa das funções que servem à preservação da vida, e só depois torna-se independente delas" (Freud, 1905/2006, p. 171). Sua afirmação de que a atividade sexual se baseia em uma necessidade de autoconservação implica na ideia de que a relação com o seio está vinculada prioritariamente à alimentação, o que Freud denomina mais tarde de escolha anaclítica de objeto. Contrapondo-se à escolha narcísica de objeto, Freud (1914/2006) aponta que a escolha objetal de tipo anaclítico está vinculada: "a) à mulher que alimenta; b) ao homem que protege, e a sucessão de pessoas substitutivas que venham a ocupar o seu lugar" (Freud, 1914/2006, p. 97). Neste sentido, enquanto as satisfações sexuais estão originalmente ligadas à absorção de alimentos, a pulsão sexual tem um objeto de satisfação fora do próprio corpo: o seio materno. Em seguida, ela se torna autoerótica, e só após o período de latência é que restabelece a relação originária, ou seja, suas escolhas objetais são modeladas pelo encontro com o seio materno da mulher que o alimentou. Esta concepção faz que Freud (1905/2006) afirme, portanto, que "O encontro do objeto é, na verdade, um reencontro" (p. 210). A importância dada por Freud à sexualidade a coloca como único fenômeno primário de ligação entre mãe e bebê. Essa concepção é revisada principalmente a partir de psicanalistas que passam a se valer de diferentes referenciais teóricos e que certamente apontam outros fenômenos de ligação, tão primários quanto Freud acreditava ser a sexualidade (Guimarães Filho, 1995).

Este é o marco que inaugura as divergências teóricas entre a psicanálise freudiana orientada pela 
primazia das pulsões e a teoria das relações objetais, bem como outras vertentes psicanalíticas que se constituíram ao longo dos anos. A teoria do apoio é uma das postulações de Freud que mais será discutida pelos teóricos da relação de objeto, justamente por colocar a necessidade de satisfação alimentar em primeiro lugar e como apoio para o estabelecimento de relações afetivas. Laplanche (1970/1985) foi um dos psicanalistas que, em sua releitura da teoria freudiana, aponta o conceito de apoio não como um fenômeno ligado ao objeto, e sim ligado à pulsão. Ele discorre: "o que é descrito por Freud é um fenômeno de apoio da pulsão, o fato de a sexualidade nascente apoiar-se num outro processo, ao mesmo tempo similar e profundamente divergente: a pulsão sexual apoia-se numa função não sexual" (Laplanche, 1970/1985, p. 24). Ainda assim, no mesmo trabalho, ele faz questão de mostrar como sua ideia não se afasta da formulada por Freud, apenas torna-a mais precisa, mantendo a diferenciação entre instinto e pulsão e corroborando com a noção de apoio e desvio da pulsão.

Tal formulação freudiana cria o paradigma pulsional, em que a finalidade principal da pulsão seria a de descarga e, portanto, a tensão primordial que se apresenta é a da fome. Mais tarde, a zona erógena ganharia independência e passaria a buscar descarga independentemente da necessidade de alimento. Porém, a partir das teorias ligadas às relações de objeto, um novo paradigma passa a vigorar. Autores independentes como Fairbairn (1940/1980), Winnicott (1945/2000, 1956/2000) e Bowlby (1969), para citar apenas alguns, passam a trabalhar baseados em algo que poderíamos chamar de paradigma relacional, no qual os aspectos interpessoais da relação estariam em evidência. Ao afirmar que a libido não busca prazer, mas sim objetos, Fairbairn (1940/1980), por exemplo, rompe com o paradigma pulsional por acreditar que a finalidade do funcionamento psíquico não é mais a descarga das pulsões elementares, mas sim o estabelecimento de vínculos com outras pessoas (Mezan, 2014).

Greenberg e Mitchell (1983) expõem de forma clara estes dois paradigmas:

Encontrar um lugar para as relações de objeto tem sido o problema conceitual central ao longo de toda a história da psicanálise, porque a teoria pulsional formulada em primeiro lugar por Freud toma a descarga de energia psíquica como seu elemento conceitual fundamental, atribuindo às relações com os outros um estatuto que não é nem central nem imediatamente aparente. Todos os principais teóricos da psicanálise tiveram que se confrontar com este problema. (pp. 379-380)

Mais adiante, os autores identificam duas estratégias de conciliação, sendo a primeira a estratégia de acomodação, que procura atribuir mais peso às relações com os outros sem retirar a pulsão de sua posição central de motivação, em que Klein e Bion desenvolveriam seus trabalhos. A segunda estratégia seria a da alternativa radical, que coloca as relações com os outros no centro da teoria, construindo o modelo do qual deriva toda a motivação, inclusive as necessidades sexuais e agressivas. Ou seja, a busca de relação - bem como a manutenção do vínculo - é colocada como causa primordial de todas as possibilidades primárias de subjetivação. Neste modelo, encontram-se Winnicott, Fairbairn e Bowlby, que, dessa forma, acabam por subverter a teoria freudiana da libido.

Por uma perspectiva interdisciplinar, traremos para a discussão estudos no campo da etologia que acreditamos ser particularmente favoráveis à tradição interpessoal. Comparando a evidência clínica trazida pela psicanálise com o ponto de vista etológico, compreendemos o que deu errado na sequência natural do desenvolvimento, o que pode ajudar a restabelecer as relações normais e naturais, principalmente no ambiente interpessoal primário (Bacciagaluppi \& Mazza, 1982). Bowlby foi um dos primeiros psicanalistas a utilizar esse campo teórico para validar suas pesquisas e sua teoria psicanalítica. A importância da observação da díade mãe-bebê convocou psicanalistas relacionais a lançarem mão de outras referências teóricas, principalmente aquelas que versam sobre os inícios do comportamento de vinculação e seus desdobramentos. Nesse âmbito, incluímos a relevância da comunicação não-verbal, os estímulos de excitação e manutenção de equilíbrio mútuo e individual (Beebe, Jaffe, \& Lachmann, 1992).

A etologia surge nas primeiras décadas do século XX e inicia seu percurso como ciência constituída a partir de trabalhos guiados por um método próprio e fundamentados num corpo teórico intimamente articulado com ele. Com filiação neodarwiniana, ela promovia a observação e a descrição dos comportamentos dos animais nos seus ambientes naturais e procurava, desde sua origem, reconstruir sua evolução filogenética (Vieira, 1983). Tal desenvolvimento da etologia acompanha em paralelo o surgimento da psicologia como ciência humana. No início do século XX, um grande debate entre vitalismo e mecanicismo invade o pensamento tanto da biologia quanto da psicologia e promove uma efervescência de descobertas.

Dentre as contribuições mais importantes desta ciência, encontramos as noções de períodos sensíveis e estampagem. Amplamente discutidos no âmbito científico, esses conceitos inauguram a ideia de que, a partir da observação animal, era possível identificar momentos específicos para que determinados comportamentos se estabelecessem. Tais conceitos dialogam com a psicanálise, na medida em que ampliam a compreensão sobre as relações de objeto e suas consequências no desenvolvimento humano. Aqui nos cabe investigar como se estabelecem os vínculos primordiais de um bebê com suas figuras de apego. 


\section{Períodos sensíveis e estampagem}

Sendo Bowlby (1969/1990) o primeiro a trazer a etologia para o campo da discussão psicanalítica, ele aponta que em muitas espécies a sensibilidade de um animal ao meio ambiente é maior numa fase do que na outra, ou seja, às vezes, um sistema comportamental é altamente sensível numa fase e depois deixa de ser. Um dos comportamentos que mais depende das "janelas" denominadas de períodos sensíveis é o que Lorenz (1935/1974) definiu como estampagem (imprinting). Este comportamento, primeiramente observado em patos e gansos, demonstra como essas aves seguem o primeiro objeto em movimento que perceberem, seja ele qual for. Segundo Bowlby, existem dois usos possíveis para o termo estampagem, um mais restrito e outro mais amplo. Lorenz (1935/1974) cunhou o termo para se referir especificamente ao comportamento de algumas aves e detalhou quatro propriedades atribuídas à estampagem:

(1) que tem lugar somente durante um breve período crítico no ciclo vital; (2) que é irreversível; (3) que é aprendizagem supra individual; e (4) que influencia padrões de comportamento que ainda não se desenvolveram no repertório do organismo, por exemplo, a escolha de um parceiro sexual. (Bowlby, 1969/1990, p. 180)

De acordo com Lorenz (1935/1974), os patos passavam por um período sensível, que ia da $13^{\mathrm{a}}$ hora depois do nascimento até a $16^{\mathrm{a}}$, além de demonstrar que uma aprendizagem do mesmo tipo ocorre mesmo quando a jovem criatura não está empenhada em seguir um objeto em movimento. Portanto, usado em sentido geral, o termo subentende sempre: o desenvolvimento de uma preferência claramente definida; uma preferência que se desenvolve com rapidez e usualmente durante uma fase limitada do ciclo vital; e uma preferência que, uma vez estabelecida, se mantém comparativamente fixa.

É importante ressaltar que as pesquisas de Lorenz são dirigidas a aves e que qualquer tentativa de transpô-las para o comportamento de outras espécies, tais como primatas não humanos, deve ser cautelosa, além de ser preciso avaliar se os processos subjacentes são distintos. Embora as formas resultantes de comportamento possam parecer quase iguais, essa semelhança se deve unicamente à evolução convergente. Além disso, a teoria do instinto de Lorenz também recebeu críticas, principalmente pautadas na sua concepção de inatismo. Daniel Lehrman, em 1953, apontou que Lorenz desenvolve ideias rígidas sobre o inatismo e a natureza da maturação de determinados comportamentos. Sua crítica incide sobre o fato de que considerar o instinto como pré-formado, herdado ou baseado em estruturas neurais específicas pode obscurecer a investigação do desenvolvimento do comportamento que, em sua opinião, deve conceber sempre a combinação entre os aspectos intraorgânicos e a relação organismo-ambiente.

A crítica desenhada por Lehrman revela a evolução sobre a precariedade de pensar um comportamento como inato ou como adquirido a partir dos processos de aprendizagem, tema amplamente discutido e já ultrapassado tanto pelo campo da psicanálise como pela biologia contemporânea. A teoria do apego, pautada em estudos etológicos, considera que a interação com o meio é fundamental para que tal comportamento se desenvolva, ainda que utilize referenciais biológicos para explicar a propensão da criança em direção à relação. Para ilustrar essa ideia, Bowlby utiliza a frase de Medawar, que afirma que "a hereditariedade propõe ... o desenvolvimento dispõe" (Medawar 1967 citado por Bowlby, 1969, p. 283).

\section{Comportamento de apego e a questão do impulso secundário}

Ao estudar o comportamento de apego - análogo ao que Lorenz chama de estampagem - Bowlby inicia sua pesquisa examinando principalmente primatas não humanos. Apesar do comportamento de apego ser observado em muitas outras espécies de animais, sua maior relevância se dá em mamíferos do que em aves, já que nos primeiros ele pode ser considerado homólogo ao que se observa no homem. Em todas as espécies, ressalta-se que este comportamento se caracteriza por dois aspectos: manutenção da proximidade com outro animal e seu restabelecimento quando ela diminui.

Lembrando que o comportamento de apego foi definido como a busca e a manutenção da proximidade de outro indivíduo, nos resta saber, portanto, quando passam a discriminar e a se apegar a determinado tipo. Harlow e Harlow (1965) acreditam que um bebê Rhesus se apega a uma mãe específica durante a primeira ou segunda semana de vida. Hinde, em comunicação pessoal a Bowlby, endossa esse ponto de vista e sublinha que, poucos dias após o nascimento, um bebê Rhesus se orienta para a mãe. Em algumas espécies de macacos, o comportamento de apego passa, em mais ou menos uma semana, a ser especialmente dirigido a certo indivíduo preferido e que, uma vez assim dirigido, a preferência se torna extremamente forte e persistente.

Antes de entrarmos na explanação sobre o comportamento de apego em humanos, vale retomar uma questão sobre a estampagem. De acordo com Lorenz, a estampagem era restritamente dirigida ao comportamento de aves, ou seja, só era possível observá-la em espécies de aves que, logo nas primeiras horas, seguiam o primeiro objeto que se movia a sua frente. Como foi dito anteriormente, o conceito de estampagem sofre mudanças e se amplia, levando este fenômeno a ser observado também em mamíferos. Salvas as devidas diferenças, o comportamento de apego que observamos em primatas se equipara à estampagem em seu sentido 
amplo. A princípio, poderia parecer que há uma nítida ruptura entre o comportamento de apego no homem e nos primatas não humanos, já que nesses últimos o apego é observado logo após o nascimento, enquanto no homem ele se desenvolve gradualmente. Porém, se observarmos com atenção, veremos que as semelhanças são muito maiores.

De acordo com Spitz (1965/1983), existem provas de que, num contexto familiar, a maioria dos bebês de três meses de idade já responde à mãe de modo diferente em relação a outras pessoas, ou seja, a discriminação perceptual está presente. Pesquisas mais recentes, como a de Bushnell (2001), comprovam que o recém-nascido já consegue reconhecer o rosto da mãe em um período muito curto e próximo ao nascimento. Esse estudo é feito a partir de observações envolvendo um sistema de codificação que identifica quando o bebê está dormindo (de olhos fechados); acordado, mas incapaz de ver sua mãe; acordado e potencialmente apto de ver sua mãe a uma distância de aproximadamente um metro, sem ver seu rosto; acordado e aparentemente olhando para o rosto de sua mãe, com distância de um metro. Ele comprova como a criança prefere o olhar da mãe a partir de um momento muito próximo ao do nascimento. $\mathrm{O}$ próprio autor diferencia este processo da estampagem animal, já que os bebês aprendem gradualmente a reconhecer o rosto da mãe durante um período de horas, mas passam a demonstrar preferências mais claras à medida que a aprendizagem se torna mais bem estabelecida. Segundo sua pesquisa, o bebê precisa acumular certa quantidade de exposição facial antes de indicar com confiança uma aparência preferencial.

$\mathrm{Na}$ pesquisa que deu origem ao artigo "Early exposure to maternal voice: effects on patterm infants development", Picciolini et al. (2014) demonstram como a exposição intrauterina à voz materna é um forte estímulo para o desenvolvimento autonômico e neurocomportamental de bebês prematuros. Os bebês do grupo de tratamento apresentaram valores mais baixos de frequência cardíaca e proporção maior de cor da pele estável em cada ponto do estudo em comparação ao grupo de controle. Os escores no desempenho da atenção visual e na qualidade dos movimentos gerais também foram melhores no grupo de tratamento do que no grupo de controle. Ou seja, tais estudos demonstram como o bebê, desde muito cedo, está apto a diferenciar a voz e o rosto materno e a demonstrar preferência por eles, sinalizando o que mais tarde irá se transformar no comportamento de apego.

Ao retornarmos aos estudos etológicos, observamos conclusões muito parecidas. Enquanto o filhote de macaco Rhesus se agarra antes de aprender a distinguir a mãe de outros macacos (objetos inanimados), o bebê humano está apto a distinguir sua mãe de outras pessoas ou objetos antes de poder se agarrar a ela ou de se deslocar ativamente em direção a ela. Assim, conclui-se que comportamento de busca é posterior ao do estabelecimento de preferência em bebês humanos.

Em pesquisas feitas anteriormente por Ainsworth (1963, 1967) e Schaeffer e Emerson (1964), comprovou-se que o comportamento de apego está nitidamente presente em crianças de seis meses e se manifesta não só pelo choro da criança quando a mãe sai do quarto, mas pelo modo como a criança reage quando ela regressa - sorriso, agitação dos braços, gorjeios de prazer. Entre os seis e nove meses, o apego à mãe fica mais consolidado e forte.

Embora existam provas de que o tipo de cuidado que um bebê recebe de sua mãe desempenha papel importante para o modo como o comportamento de apego se desenvolve, não se deve esquecer em que medida a criança inicia a interação e como influencia na forma que ela assume. Existe um papel ativo do bebê humano em direção à relação. Ainsworth (1963) demonstra que a característica do comportamento de apego que impressiona é como a própria criança toma a iniciativa de procurar a interação. De dois meses em diante e ao longo do primeiro ano de vida, os bebês gandas se mostravam menos passivos e receptivos e mais ativos na busca de interação. Schaffer (1963) aponta que as crianças parecem ditar o comportamento dos pais pela insistência de suas exigências. Em sua pesquisa, as mães relatavam que eram forçadas a responder a seus bebês. Além de chorar, um bebê chama persistentemente e, quando é atendido, orienta-se para a mãe ou outra companhia. Não só o bebê provoca respostas de seus acompanhantes, mas também mantém e dá forma às respostas deles, reforçando algumas e não outras.

Mais tarde, autores como Tronick, Morelli e Ivey (1992), Rothbaum, Weisz, Pott, Miyake e Morelli (2000), entre outros, criticaram algumas das conclusões apresentadas por Ainsworth e Bowlby sobre a teoria do apego. De acordo com eles, há um enfoque ocidental nas pesquisas iniciais sobre o apego, que indica um pensamento etnocêntrico sobre o desenvolvimento das relações iniciais. Ribas e Moura (2004) apontam que:

o posicionamento desses autores foi bastante crítico na medida em que eles negam a universalidade das três hipóteses centrais da teoria do apego, que são as hipóteses da sensitividade, da competência e da base segura. Os autores utilizam observações comparativas realizadas entre Japão e Estados Unidos, e destacam que a teoria do apego requer mudanças fundamentais quando aplicada a culturas não ocidentais. (pp. 317-318)

Os estudos posteriores sobre a teoria do apego inclusive os que versam sobre aspectos transculturais lapidaram pontos pouco trabalhados por Bowlby e Ainsworth, mas de modo algum negaram a importância de suas contribuições. Eles apenas apontam a plasticidade do instinto e como ele pode se expressar de diferentes 
formas de acordo com a cultura. Isso incide, inclusive, no modo de pensar a qualidade das interações e as trocas sociais desempenhadas pelas figuras de cuidado e pelas crianças.

Seguindo essa linha, pesquisas recentes (Beebe, 2006; Beebe et al., 1992; Tronick, 1989) no campo da interação e comunicação diádica entre mãe-bebê demonstram que, apesar de existir uma natureza recíproca na influência de um sujeito sobre o outro, isso não significa que ambos se afetam de forma simétrica ou de jeitos semelhantes. A mãe tem grande alcance, flexibilidade e capacidade, mas a criança desempenha papel importante em sua capacidade de buscar ou evitar engajamento.

Diante de tantas evidências que demonstram o papel ativo da criança em direção à interação e ao estabelecimento de uma relação de apego, a teoria do impulso secundário se torna ainda mais questionável. Talvez o experimento etológico mais importante para a discussão psicanalítica sobre o impulso secundário seja o de Harlow com macacos Rhesus. No conhecido experimento, os filhotes são expostos a um modelo cilíndrico de arame ou um modelo semelhante, mas coberto de tecido macio. A mamadeira podia ser colocada em qualquer um dos dois modelos e os resultados mostraram que, independentemente de qual fosse o modelo que fornecesse alimento, os bebês tratavam rapidamente de passar a maior parte do tempo junto ao modelo de pano. Portanto fica claro que o "conforto de contato" acarretou o comportamento de apego, ao passo que o alimento não.

Alguns psicanalistas que ainda sustentam a teoria do impulso secundário, como Assoum (1993/1996), Laplanche (1970/1985), entre outros, argumentam que nela reside a explicação sobre a elevada frequência de sintomas orais em pacientes neuróticos e psicóticos. Essa explicação segue a linha da teoria pulsional, já que entendem estes sintomas como sendo regressões a uma fase libidinal anterior. Winnicott (1954/2000) esclarece este aspecto ao se aprofundar na teoria da regressão que, de acordo com ele, oferece a possibilidade de correção de uma falha original ambiental, sendo parte de um processo de cura. Regredir em ambiente analítico a um período de dependência absoluta - onde a oralidade era predominante - é fundamental em casos em que se observa o congelamento de experiências em momentos iniciais da vida do paciente.

Além disso, por meio de uma substituição simbólica, os sintomas orais podem ser considerados por um paciente como o equivalente da relação com uma pessoa, ou seja, a parte representa o todo. Parece também provável que, em muitos casos, uma atividade oral seja classificada como atividade de deslocamento, ou seja, uma atividade que é evocada quando outra é frustrada e que parece ocorrer fora do contexto. Foi observado por Tinbergen (1940) e Kortlandt (1940) que, tanto na gaivota-argêntea como no corvo-marinho-de-faces-brancas, a iminência do combate entre rivais dava lugar ao aparecimento de esquemas corporais fora de contexto, desconexos em relação aos comportamentos em curso. O estudo aprofundado mostrou que as atividades deslocadas apareciam sobretudo por conta de conflitos motivacionais ligados à agressividade e à sexualidade, entendendo-se que indivíduos dominados por impulsos instintivos antagônicos, contraditórios ou frustrados desencadeavam facilmente esse tipo de comportamento. Notou-se também que tais atividades se tornavam estímulos-sinais portadores de uma mensagem social e investidos de função semântica. Em outras palavras, propõe-se que, quando o apego de uma criança a sua mãe é frustrado, desenvolve-se a sucção ou a voracidade como uma atividade nãosimbólica fora de contexto. Tanto em Chimpanzés como em Rhesus, observa-se grande excesso de sucção autoerótica quando criados sem mães às quais possam se aconchegar.

Em seis crianças de campo de concentração observadas por Anna Freud e Sophie Dann (1951/1969), constatou-se que todas eram inveteradas sugadoras de polegar. As autoras atribuem isso ao fato de que, para todas essas crianças, "o mundo objetal era comprovadamente decepcionante" (p. 201). Elas prosseguem dizendo:

Que o excesso de sucção estava em proporção direta com a instabilidade de suas relações objetais foi confirmado no fim do ano quando as crianças souberam que estavam prestes a deixar Bulldogs Bank e quando a sucção, durante o dia, tornou-se uma vez mais preponderante em todas elas. Essa persistência da gratificação oral . . . flutuava de acordo com as relações entre as crianças e o meio ambiente. (Freud \& Dann, 1951/1969, p. 201)

Se esse processo ocorre em bebês humanos, possivelmente podemos explicar, por meio deles, alguns dos sintomas orais que se manifestam em indivíduos mais velhos quando as relações objetais se tornam difíceis. Fairbairn (1941/1980) já salientava que a teoria clássica da libido deveria ser transformada em uma "teoria do desenvolvimento baseada essencialmente nas relações de objeto" (p. 25). Ele acrescenta que a maior limitação da teoria freudiana seria a de que ela confere o status de atitudes libidinais a inúmeras manifestações que são apenas técnicas do ego para regular as relações de objeto. De acordo com ele, o autoerotismo é uma técnica que o indivíduo busca para se prover de um objeto que não pode obter, ou seja, que está ausente. A ausência desse objeto por um período que o bebê não é capaz de suportar desencadeia uma série de atividades consideradas deslocadas pela etologia.

Alguns autores (Beebe, 2006; Tronick, 1989) trazem novas considerações acerca da atividade de chupar 
o polegar. Em pesquisas que avaliaram a interação entre mãe e bebê, nota-se que chupar o polegar pode se associar a diferentes fatores, dependendo do tipo de relação que se estabelece entre a díade. A ideia de autorregulação nos ajuda a compreender que, em muitos momentos da interação, a criança precisa se retirar para regular suas excitações internas. Porém elas fazem parte de um sistema de comunicação afetiva que se desenha concomitantemente à interação da díade. Esse momento de retirada da criança comunica para a mãe que é preciso esperar até que o contato se restabeleça. Chupar o polegar, aqui, significa que a criança permanece na interação, mas precisa se equilibrar internamente. Quando a mãe não é capaz de esperar esse momento e força a manutenção de contato direto, a criança se retrai mais e permanece ainda mais envolvida nas suas atividades autocalmantes.

Winnicott (1951/2000), ao formular a ideia de objetos e fenômenos transicionais, inclui em suas observações fenômenos que, longe de exercerem função transicional, operam como artifícios tranquilizadores ou confortadores. A função de um objeto transicional seria a de proporcionar uma gradual desilusão do bebê, permitindo que ele comece a vivenciar as relações que existem entre o mundo externo e o interno. $\mathrm{O}$ objeto transicional e o fenômeno transicional aparecem como facilitadores desta relação, ao passo que se localizam em uma zona intermediária da experiência humana. Eles podem se tornar objetos ou fenômenos tranquilizadores quando a função que exercem não opera como facilitadora. Eles servem apenas para confortar a ausência da mãe, mas não necessariamente permitem que a criança atravesse essa separação de forma saudável.

\section{A gênese da comunicação humana}

Ao partirmos da ideia de que o indivíduo estabelece uma vinculação primária com sua mãe (ou figura materna), independentemente da necessidade de alimento - e que tal comportamento é observado em inúmeras espécies -, deparamos com outras investigações importantes, principalmente no campo da comunicação humana. Anteriormente, apontamos que determinados comportamentos surgem em substituição a necessidades afetivas frustradas. A sucção seria a mais ilustrativa, justamente por demonstrar que, nestes casos, não é a falta de alimento ou a reativação do prazer de ser alimentado que está em jogo, mas muitas vezes a falta de proximidade e interação afetiva com a figura de vinculação. Este sinal comunica algo. Assim, como o ser humano entra no mundo da linguagem e, como isso, o diferencia de outros animais, é uma questão que nos interessa.

$\mathrm{Na}$ prática clínica, o psicanalista se vê invariavelmente observando não só o que é dito pelo paciente, mas também todo seu comportamento gestual, suas pausas, entonações, o ritmo de suas conversas etc. A forma como cada paciente comunica aquilo que sente ou vive nos indica sua condição psíquica e nos oferece a possibilidade de investigar como suas relações primárias e mais importantes se desenvolveram.

Beebe et al. (1992) expõem suas pesquisas no âmbito das origens da comunicação entre a díade mãe e bebê. De acordo com eles, a comunicação pode ser estudada por duas vertentes. A primeira delas seria aquela que lida com o conteúdo linguístico da mensagem, incluindo seus desejos e fantasias, e na qual a psicanálise da primeira metade do século XX mais depositou seu interesse e suas investigações. A segunda vertente da comunicação passou a se dedicar à forma como a comunicação vem sendo estudada nas interações sociais infantis, ou seja, sobre o enquadramento da interação. A partir dessa perspectiva, a qualidade afetiva da relação passa a ser observada a partir do ritmo compartilhado, dos movimentos corporais, do ritmo de fala e de silêncio que se estabelece (Beebe et al., 1992).

Várias tradições de pesquisa que englobam o desenvolvimento ao longo da vida tendem a se concentrar nos estudos sobre a autorregulação ou sobre aqueles que versam sobre a regulação interativa. Psicofisiologia, endocrinologia e abordagens maturacionais do desenvolvimento examinaram a autorregulação, ou seja, as estratégias individuais do bebê de manter um equilíbrio homeostático. Eles abordaram questões como excitação, ritmo, organização de ciclos de vigília do sono, respiração e alimentação, além de vários padrões patológicos de reatividade individual. Por outro lado, disciplinas como etologia e psicologia social se concentraram na regulação diádica, examinando questões como contato visual, ritmos de conversação, jogos e sinalização. Nessas abordagens de regulação interativa, a díade é vista como um sistema de participação conjunta, com formas organizacionais compartilhadas, tais como ritmos compartilhados ou exibições afetivas (Condon \& Sander, 1974). Pesquisadores e psicanalistas passam a se interessar pelo modelo bidirecional ou de mútua influência, justamente por observarem que tal modelo se torna o protótipo das relações posteriores, inclusive da relação paciente-analista.

As atividades autorregulatórias do bebê fazem parte da comunicação tanto quanto as atividades dirigidas ao outro. Em um primeiro momento, chupar o polegar ou desviar o olhar são atividades dirigidas ao cuidador, que precisa estar atento a essa comunicação. Os momentos de retirada e reclusão enviam uma mensagem à mãe de que a criança precisa equilibrar seu estado interno para então voltar a interagir. Se a mãe falha nessa compreensão, a criança se vê obrigada a dirigir sua meta para uma regulação interna, no intuito de controlar suas respostas emocionais (Tronick, 1989). O que antes era uma atividade interativa passa a ser uma tentativa individual de manter seu mundo interno equilibrado.

Boris Cyrulnick (1991), em seu livro O nascimento do sentido, salienta que o nascimento da palavra está diretamente ligado à noção de cultura que estabelecemos e aos conjuntos comportamentais socialmente codificados 
que a apoiam. De acordo com ele, "a prática da palavra aparece indissociável de gestos, de sentimentos, e de comportamentos determinados" (Cyrulnick, 1991, p. 121). Os aspectos paralinguísticos da comunicação são enquadres necessários para que a comunicação com a linguagem verbal ocorra. Deve-se encarar a comunicação humana como um processo de mútua afetação, em que duas correntes de comportamento estão afetando uma o comportamento da outra. Quando isso ocorre, mudanças cognitivas e afetivas também estão acontecendo (Beebe et al., 1992).

O discurso etológico entende que a comunicação é feita de sonoridades, melodias ritmadas por silêncios, "num co-texto de mímicas faciais que exprimem emoções verbais, gestos, que sublinham ou contradizem o discurso, e de posturas que dão a palavra ao espaço" (Cyrulnick, 1991, p. 123). Ao fazer da palavra um objeto etológico, o observador procura tornar observável o modo como dois seres falantes fazem para falar e a forma que isso toma para comunicar.

Para melhor avaliar os movimentos de expressão, Eibl-Eibesfeldt (1974) utiliza o experimento de J. Thompson (1941), que observou o comportamento de bebês cegos/cegos e surdos de nascimento. Nos bebês cegos de nascimento se podia observar também o sorriso, o riso e o choro, assim como as expressões de nojo, cansaço, medo e tristeza, porém estes bebês não podiam tê-las aprendido por imitação. Com o passar do tempo, os bebês cegos de nascimento sorriam menos que os bebês que viam ou que haviam ficado cegos posteriormente.

Em resumo, toda uma série de padrões de comportamento - muitos deles bastante complicados e que são típicos de seres humanos - se desenvolve também nos bebês surdos e cegos, e são, portanto, adaptações filogenéticas. Nesses bebês, se desenvolvem algumas características do comportamento social, inclusive contra os esforços educacionais, além de tendências agressivas. Se não existissem as adaptações filogenéticas, esses bebês necessitariam de muitos passos distintos para estabelecer padrões de comportamento tão complicados. Por isso a teoria do reforço positivo pode ser rebatida com a ideia da adaptação filogenética. As hipóteses de que os bebês têm de ter aprendido os complicados movimentos de expressão carece de fundamento. De toda forma, para manter essa hipótese, devem-se admitir algumas disposições inatas a aprendizagens especiais e, portanto, apoiar-se ainda mais no conceito etológico de adaptações filogenéticas do comportamento.

Eibl-Eibesfeldt (1974) entende que existem complicadas sequências de comportamento que pressupõem um diálogo entre a mímica e a palavra. Essas pessoas surdas e cegas carecem dessa possibilidade de comunicação. Se observarmos semelhanças nos gestos, poderemos chegar à conclusão de que existe uma raiz herdada de tal comportamento. Entendendo que os homens têm uma inclinação a evoluir culturalmente, como demonstra a evolução da língua, é possível observarmos uma constância de formas primárias de expressão em todos os povos; podemos falar de certas invariações de nossas expressões emocionais.

A zoossemiótica permitiu analisar que a comunicação animal descreve uma sintaxe comportamental feita de sinais visuais, olfativos e acústicos, que se encadeiam e se harmonizam para permitir aos dois participantes da comunicação a sincronização, numa verdadeira pragmática da semiótica animal (Cyrulnick, 1991). Eles podem, portanto, comunicar com grande riqueza mundos interiores muito organizados, diferentes e, por vezes, individuais. Todavia a semântica animal requer mais cuidado ao ser explicada, já que nenhum animal não humano pode transmitir uma informação referente a um acontecimento totalmente ausente. A linguagem e o pensamento animal se enraízam no contexto, diferentemente do homem que é capaz de criar um mundo totalmente ausente, inexistente no contexto.

Alguns autores que se dedicaram à investigação dos estados autísticos (Cyrulnick, 1991; Mahler, 1975, 1982; Tustin, 1972/1975, 1981/1984) afirmam que as crianças que não têm acesso à linguagem têm uma competência genética intacta para ela, tendo apenas o cérebro e o aparelho para perceber o mundo deformados. Mesmo nessa condição, não devemos entender que tais crianças permanecem estagnadas em relação ao desenvolvimento. Pelo contrário, elas lutam arduamente contra seu mundo, tal como nós lutamos contra o nosso, mantendo o desenvolvimento em curso, apenas sobre outras bases e seguindo outras direções. Neste ponto, entendemos que a noção de períodos sensíveis nos esclarece sobre a importância de determinados movimentos ocorrerem em momentos específicos do desenvolvimento, para que a inserção do sujeito no mundo da linguagem aconteça.

Stern (2004) fala sobre o autismo como uma evidência da distinção entre o sistema motivacional de apego e a intersubjetividade. Crianças autistas mostram habilidades de intersubjetividade muito prejudicadas, mas estão ligadas aos pais, o que denota a existência de comportamentos de apego claros e identificáveis, mesmo que seus padrões sejam desviados. As pesquisas sobre apego não medem a força do apego, apenas os padrões comportamentais usados para se apegar, como apego seguro, apego ansioso e apego ansioso com evitação. Nesse sentido, não há como sugerir que crianças autistas pareçam desapegadas ou fracamente apegadas. Separar esses dois sistemas motivacionais - apego e intersubjetividade - é importante tanto clínica como teoricamente. É possível ser apegado sem compartilhar intimidade intersubjetiva. De acordo com Stern (2004):

O que está em jogo é a intimidade e a pertença psicológicas, que desempenham um papel poderoso na formação e manutenção de grupos. $\mathrm{O}$ pertencimento psicológico é diferente dos vínculos físicos, sexuais ou de dependência. É uma ordem separada de parentesco. É uma forma de pertencer 
ao grupo que é única para os seres humanos ou que aponta um enorme salto quantitativo e quantitativo em nossa espécie. Alguém poderia argumentar que o salto é a linguagem. Mas sem a intersubjetividade, a linguagem não poderia se desenvolver. (p. 100, tradução nossa)

Assim, o autor salienta que o comportamento de apego está a serviço da intersubjetividade e viceversa. Desse modo, para crianças autistas, que têm a habilidade para a intersubjetividade prejudicada, o acesso à linguagem torna-se também prejudicado.

No mesmo grupo de crianças autistas encontramos as crianças abandonadas, ou "crianças armário", aquelas cuja família a deixa privada de qualquer contato com outros indivíduos. Elas vivem em total privação social e sensorial. Portanto não são necessários apenas prérequisitos neurológicos para que se abra o acesso à linguagem, mas também pré-requisitos afetivos: "O sistema comportamental que 'suporta' a palavra e a faz advir, supõe a presença em redor da criança, de qualquer outro ser a quem falar, para quem falar. ... Na falta dessa pessoa, o acesso será fechado" (Cyrulnick, 1991, p. 63). De todo modo, esse processo não é irreversível, tendo em vista a plasticidade do cérebro humano. Porém crianças que sofreram tamanha privação, mas que foram reabertas à palavra, ficarão com marcas da privação afetiva inicial. O bebê humano se comunica com o meio que o circunda por meio de seus sentidos, ou seja, a sensorialidade é sua ferramenta de comunicação.

De acordo com Ogden (1989), o que ele denomina de posição autista-contígua serviria como preparação para a criação dos símbolos, que seriam mediados pela experiência do fenômeno transicional quando segue seu curso normal de desenvolvimento. Essa faceta da experiência estaria ligada aos modos sensoriais com os quais um bebê vivencia o ambiente que o circunda. O colapso desta experiência pode resultar em um "aprisionamento tirânico" dentro de um sistema fechado de sensações corporais, que precedem o desenvolvimento do espaço potencial. Crianças autistas, ou mesmo aquelas que sofreram forte abandono em estágios muito precoces, vivem aprisionadas em seu mundo sensorial, estabelecendo com a linguagem uma relação particular e, muitas vezes, deficitária. Paulo Duarte Guimarães Filho (1995) é outro psicanalista que busca investigar as relações que a criança autista estabelece com seus outros primordiais a partir de estudos etológicos. De acordo com ele, a criança autista pode acabar substituindo sua percepção e identificação da figura materna por outros objetos em função de seus atributos sensoriais. Por este motivo elas apresentam ligações importantes e muito intensas com objetos inanimados, justamente por eles produzirem uma sensação tátil de dureza. Francis Tustin (1981) também salienta a preponderância de "objetos autísticos" para crianças psicóticas e autistas, que os utilizam de forma desvinculada de sua função primordial, já que sua relevância recai sobre o domínio das sensações.

Guimarães Filho (1995) retoma o conceito de estampagem para demonstrar como a vinculação ao semelhante precisa ocorrer dentro de um período sensível, fundamental para que outras ações do desenvolvimento ocorram.

. . em diversas espécies há um período chamado sensível, durante o qual pode ocorrer o reconhecimento de um outro ser da mesma espécie. Se este não estiver presente, conforme é mostrado em inúmeros trabalhos experimentais, a disposição inata para a ligação com um semelhante será preenchida por um outro tipo de objeto presente no ambiente (Guimarães Filho, 1995, p. 226).

Apesar da analogia com o autismo humano ser óbvia, o autor reconhece que a criança autista não está totalmente desvinculada de seus semelhantes, tampouco se dá apenas em crianças que ficaram totalmente isoladas de outras pessoas. Ao mesmo tempo, é frequente que tais crianças tenham vivido um afastamento parcial de seus principais cuidadores.

A abordagem etológica da palavra, por sua vez, nos permite sustentar que existe um pensamento sem linguagem. De acordo com Cyrulnick (1991):

O que diferencia o homem dos não homens não é tanto a palavra que pode ser considerada sob a forma material como um objeto sonoro pertencente então a qualquer ser vivo; é sobretudo a aptidão louca para semiotizar. A partir daqui tudo pode ser sinal. Uma coisa pode se transformar em objeto historizado, ruído pode organizar-se em música ou em palavra, uma cor pode ordenar-se em quadro, uma série de gestos pode tornar-se dança ou representação teatral (pp. 128-129).

Para que isso ocorra, é necessário que a criança encontre uma figura de vinculação, que permitirá que a palavra se enraíze no corpo da criança em desenvolvimento, gerando relações afetivas e sociais e transformando seu mundo interpessoal. Eibl-Eibesfeldt (1974), por um ponto de vista da etologia clássica, já havia apontado para esse caminho que vai do inato ao adquirido. Tomando a família como ponto de partida de seu estudo, ele identifica que a relação de uma mãe com seu filho é natural e bem determinada. Essa relação se estabelece primeiro graças a uma série de impulsos inatos tais como sugar, abraçar, chorar, sorrir, seguir, e as correspondentes reações da mãe que, respondendo a determinados estímulos desencadeadores, acolhe seu filho. Podemos pensar que a fragilidade do bebê humano exige que os cuidados parentais sejam maiores, mais extensos e sofisticados (Silk, 1999). É desse modo que se constrói a habilidade para intersubjetividade. Sem uma 
base intersubjetiva, a linguagem não pode surgir, sendo essa uma das razões que levam crianças abandonadas, privadas de contato afetivo-sensorial ou autistas a terem tanta dificuldade com a aquisição da linguagem.

Assim como Bowlby (1969/1990), Eibl-Eibesfeldt (1974) indica que as teorias segundo as quais o bebê se liga à mãe apenas secundariamente, porque ela satisfaz suas necessidades de alimento e calor, não se apoiam em fatos. Tampouco se apoiaria em fatos a afirmação de que o bebê se ressente de ter nascido e trata de voltar ao seio materno, tal como indicava Melanie Klein. "O vínculo da mãe com seu filho é um vínculo primário e não se desenvolve pelo caminho do 'amor a si mesmo' do bebê porque será alimentado por sua mãe" (Eibl-Eibesfeldt, 1974, p. 525).

\section{Considerações finais}

Sendo assim, concluímos que a etologia como ciência comparada do comportamento tem muito a contribuir aos estudos psicanalíticos do desenvolvimento humano bem como dos estados mentais decorrentes. A ideia que Freud sustentou ao longo de sua obra em relação à teoria do apoio visivelmente não se comprova através de fatos empíricos como mostram as pesquisas posteriores, o que oferece um novo panorama de conceituações sobre a ontogênese humana. Aquilo que na clínica se apresenta como modos de comunicação possui sua raiz nas íntimas relações de apego com uma figura de vinculação, comportamento básico e primário na maioria das espécies, incluindo o homem. A forma como cada indivíduo comunica o que há em seu mundo interno mostra-nos o curso que suas relações primordiais tomaram. Psicóticos, neuróticos e borderlines possuem diferentes modalidades de comunicação, mas certamente todas são efeitos de como o desenvolvimento dessa relação inicial se deu. O discurso psicanalítico, portanto, encontra-se na interseção entre o intrinsecamente biológico e a subjetividade humana. Se por um lado valoriza os aspectos fundamentalmente orgânicos de um comportamento, por outro, ao utilizar a linguagem como meio de cura, compreende as múltiplas formas pelas quais tais comportamentos se manifestam, de acordo com cada subjetividade.

\section{Attachment and communication: child development from the perspective of ethology and psychoanalysis}

Abstract: This article addresses the primary bond of children to their mothers as primordial in human development. Based on an interdisciplinar perspective uniting ethology and psychoanalysis, we go through the notions of sensitive periods, imprinting and attachment behavior, establishing a parallel between animal and human development. Then, we discuss modes of communication and their roots in attachment relationships established by the individual at the beginning of life, taking into account clinical practice in psychoanalysis with the help of ethological theory.

Keywords: attachment theory, communication, ethology, psychoanalysis, leaning-on theory.

\section{Attachement et communication : considérations sur le développement de l'enfant sous la perspective de l'éthologie et de la psychanalyse}

Résumé : Cet article vise à aborder le lien primaire entre l'enfant et sa mère, en le plaçant comme primordial dans le développement humain. Dans la perspective interdisciplinaire de l'éthologie et de la psychanalyse, nous abordons les notions de périodes sensibles, de comportement d'estampage et d'attachement, établissant un parallèle entre les développements humain et animal. Ensuite, nous discutons les modes de communication et leurs racines dans les relations d'attachement que l'individu établit au début de sa vie, en tenant compte de la clinique psychanalytique à l'aide de la théorie éthologique.

Mots-clés : théorie de l'attachement, communication, éthologie, psychanalyse, théorie de l'étayage.

\section{Apego y comunicación: considerando el desarrollo infantil desde la perspectiva de la etología y el psicoanálisis}

Resumen: Este artículo tiene como objetivo abordar el vínculo primario del niño con su madre al considerarlo primordial en el desarrollo humano. Desde la perspectiva interdisciplinaria de la etología y el psicoanálisis, pasamos por las nociones de períodos sensibles, estampación y comportamiento de apego, estableciendo un paralelismo entre el desarrollo animal y humano. Luego, discutimos los modos de comunicación y sus raíces en las relaciones de apego que el individuo establece al comienzo de la vida, teniendo en cuenta la clínica psicoanalítica y la teoría etológica.

Palabras clave: teoría del apego, comunicación, etología, psicoanálisis, teoría del apoyo. 


\section{Referências}

Ainsworth, M. D. (1963). The development of infant-mother interaction among the Ganda. In B. M. Foss (Ed.), Determinants of infant behavior (Vol. 2, pp. 67-103). London: Methue.

Ainsworth, M. D. (1967). Infancy in Uganda: Infant care and the growth of attachment. Baltimore: Johns Hopkins University Press.

Assoum, P. L. (1996). Metapsicologia freudiana: uma introdução. Rio de Janeiro, RJ: Zahar. (Trabalho original publicado em 1993)

Bacciagaluppi, M., \& Mazza, M. B. (1982). The Relevance of ethology to interpersonal psychodynamics and to wider social issues. Journal of The American Academy of Psychoanalysis, 10(1), 85-111. doi: 10.1521/ jaap.1.1982.10.1.85

Beebe, B. (2006). Co-constructing mother-infant distress in face-to-face interactions: Contributions of microanalysis. Infant Observation, 9(2), 151-164. doi: 10.1080/13698030600810409

Beebe, B., Jaffe, J., \& Lachmann, F. (1992). A dyadic systems view of communication. In: N. Skolnick \& S. Warshaw (Orgs.), Relational views of psychoanalysis (pp. 61-81). Hillsdale: Analytic Press.

Bowlby, J. (1990). Apego e perda: Apego (Vol. 1). São Paulo, SP: Martins Fontes. (Trabalho original publicado em 1969)

Bushnell, I. (2001). Mother's face recognition in newborn infants: Learning and memory. Infant and Child Development, 10(1), 67-74. doi: 10.1002/icd.248

Condon, W., \& Sander, L. (1974). Synchrony demonstrated between movements of the neonate and adult speech. Child Development, 45, 456-462. doi: 10.2307/1127968

Cyrulnick, B. (1991). O nascimento do sentido. Lisboa: Instituto Piaget.

Eibl-Eibesfeldt, I. (1974). Etologia: Introduccion al estudo comparado del comportamiento. Barcelona: Omega.

Fairbairn, R. (1980). Fatores esquizoides na personalidade. In R. Fairbairn, Estudos psicanaliticos da personalidade (1952) (pp. 3-22). Rio de Janeiro, RJ: Interamericana. (Trabalho original publicado em 1940)

Fairbairn, R. (1980). Uma revisão da psicopatologia das psicoses e psiconeuroses. In R. Fairbairn, Estudos psicanalíticos da personalidade (1952) (pp. 23-46). Rio de Janeiro, RJ: Interamericana. (Trabalho original publicado em 1941)

Guimarães Filho, P. D. (1995). Alguns achados na fronteira da psicanálise com a etologia e com a psicologia do desenvolvimento. In L. C. U. Junqueira Filho (Org.), Corpo-mente: Uma fronteira móvel (pp. 223-233). São Paulo, SP: Casa do Psicólogo.

Freud, A., \& Dann, S. (1969). An experiment in group upbringing. In A. Freud, Indications for child analysis and other papers, 1945-1956 (pp. 163-229). London: Hogarth Press. (Trabalho original publicado em 1951)
Freud, S. (2006). Três ensaios sobre a teoria da sexualidade. In Edição standard brasileira das obras psicológicas completas de Sigmund Freud (J. Salomão, trad., vol. 7, pp. 119-231). Rio de Janeiro, RJ: Imago. (Trabalho original publicado em 1905)

Freud, S. (2006). Sobre o narcisismo: uma introdução. In Edição standard brasileira das obras psicológicas completas de Sigmund Freud (J. Salomão, trad., vol. 14, pp. 81-111). Rio de Janeiro, RJ: Imago. (Trabalho original publicado em 1914)

Greenberg, J. \& Mitchell, S. (1983). Object relations in psychoanalytic theory. Cambridge: Harvard University Press.

Harlow, H. F. \& Harlow, M. K. (1965). The affectional systems. In A. Schrier, H. Harlow, \& F. Stollnizt (Orgs.), Behavior of nonhuman primates (vol. 2, pp. 287-334). New York: Academic Press.

Kortlandt, A. (1940). Eine Ubersicht der angeborenen Verhaltensweisen des mittleleuropäischen Kormorans (Phalacrocorax carbosinensis), ihre Funktion, ontogenetische Entwicklung und phylogenetische Herkunft. Archives Neerlandaises de Zoologie, 4, 401-442.

Laplanche, J. (1985). Vida e morte em psicanálise. Porto Alegre, RS: Artes Médicas. (Trabalho original publicado em 1970)

Lehrman, D. S. (1953). A critique of Konrad Lorenz's theory of instinctive behavior. The Quarterly review of Biology, 28(4), 337-336.

Lorenz, K. (1974). Studies in animal and human behaviour. Cambridge: Harvard University Press. (Trabalho original publicado em 1935)

Mahler, M. (1982). O processo de separação-individuação. Rio de Janeiro, RJ: Zahar.

Mahler, M., Pine, F. \& Bergman, A. (1975). O nascimento psicológico da criança: Simbiose e individuação (2a ed.). Rio de Janeiro, RJ: Zahar.

Mezan, R. (2014). O tronco e os ramos. São Paulo, SP: Companhia das Letras.

Ogden, T. (1989). The primitive edge of experience. New Jersey: Jason Aronson.

Picciolini, O., Porro, M., Meazza, A., Giannì, M. L., Rivoli, C., Lucco, G., . . . Mosca, F. (2014). Early exposure to maternal voice: Effects on preterm infants development. Early Human Development, 90(6), 287-292. doi: 10.1016/j.earlhumdev.2014.03.003

Ribas, A. F. P. \& Moura, M. L. S. (2004). Responsividade materna e teoria do apego: Uma discussão crítica do papel de estudos transculturais. Psicologia: Reflexão $e$ Critica, 17(3), 315-322.

Rothbaum, F., Weisz, J., Pott, M., Miyake, K., \& Morelli, G. (2000). Attachment and culture: Security in the United States and Japan. American Psychologist, 55, 1093-1104. 
Silk, J. B. (1999). Why are infants so attractive to others? The form and function of infant handling in bonnet macaques. Animal Behaviour, 57(5), 1021-1032.

Schaeffer, H. R., \& Emerson, P. E. (1964). The development of social attachments in infancy. Monographs of the Society for Research in Child Development, 29(3), 1-77. doi: $10.2307 / 1165727$

Spitz, R. (1983) O primeiro ano de vida. São Paulo, SP: Martins Fontes. (Trabalho original publicado em 1965)

Stern, D. (2004). The present moment in psychotherapy and everyday life. New York: Norton.

Tinbergen, N. (1940). Die Uebersprungbewegung. Zeitschrift für Tierpsychologie, 4, 1-40.

Tronick, E. (1989). Emotions and emotional communication in infants. American Psychologist, 44(2), 112-119.

Tronick, E. Z., Morelli, G. A., \& Ivey, P. K. (1992). The Efe forager infant and toddler's pattern of social relationships multiple and simultaneous. Developmental Psychology, 28, 568-577.

Tustin, F. (1975). Autismo e psicose infantil. Rio de Janeiro, RJ: Imago. (Trabalho original publicado em 1972)

Tustin, F. (1984). Estados autísticos em crianças. Rio de Janeiro, RJ: Imago. (Trabalho original publicado em 1981)
Vieira, A. B. (1983). Etologia e ciências humanas. Brasília, DF: Imprensa Nacional.

Winnicott, D. W. (2000). Desenvolvimento emocional primitivo. In D. W. Winnicott, Da pediatria à psicanálise (pp. 218-232). Rio de Janeiro, RJ: Imago. (Trabalho original publicado em 1945)

Winnicott, D. W. (2000). Objetos transicionais e fenômenos transicionais. In D. W. Winnicott, Da pediatria à psicanálise (pp. 316-331). Rio de Janeiro, RJ: Imago. (Trabalho original publicado em 1951)

Winnicott, D. W. (2000). Aspectos clínicos e metapsicológicos da regressão no contexto psicanalítico. In D. W. Winnicott, Da pediatria à psicanálise (pp. 374-392). Rio de Janeiro, RJ: Imago. (Trabalho original publicado em 1954)

Winnicott, D. W. (2000). Preocupação materna primária. In D. W. Winnicott, Da pediatria à psicanálise (pp. 399-405). Rio de Janeiro, RJ: Imago. (Trabalho original publicado em 1956)

Recebido: 09/11/2019

Revisado: 16/09/2020

Aprovado: 08/10/2020 